ISSN: 2644-1209

\title{
Headache and Eye-A Mutual Relationship
}

\section{Pratyush Dhakal* and Amrita Samanta}

Carl Zeiss India (Bangalore), India

*Corresponding author: Pratyush Dhakal, Center for Application Research in India, Carl Zeiss India (Bangalore) Pvt Ltd, Bangalore, India

\section{Opinion}

Headache is probably the commonest neurological complaint worldwide. According to the World Health Organization (WHO), $1.7-4 \%$ of the adult population of the world have headaches on 15 or more days every month. Sometimes these symptoms are misunderstood and confused with Migraine Attacks or with normal tension headaches. It is also one of the commonest problems because of which people come for a glass/eye check-up. Very often the belief is that a change of eye power is the reason for headaches. Students who constantly keep reading books or keep doing their academic exercises have more chances to suffer from eye related problems like Eye strain, Fatigue, Eye pain, Headache etc. When a patient comes to you with complaints like headache after some continuous reading it is important to be able to distinguish if it is related to the eyes or not. Headache can be felt in a variety of places on the head, including the temples, sinuses, forehead and back of the head. Eye pain associated with a headache can be caused by a few different types of headaches, as well as other seemingly unrelated conditions. But regardless of the cause, this type of pain can be mild, moderate, or even unbearable

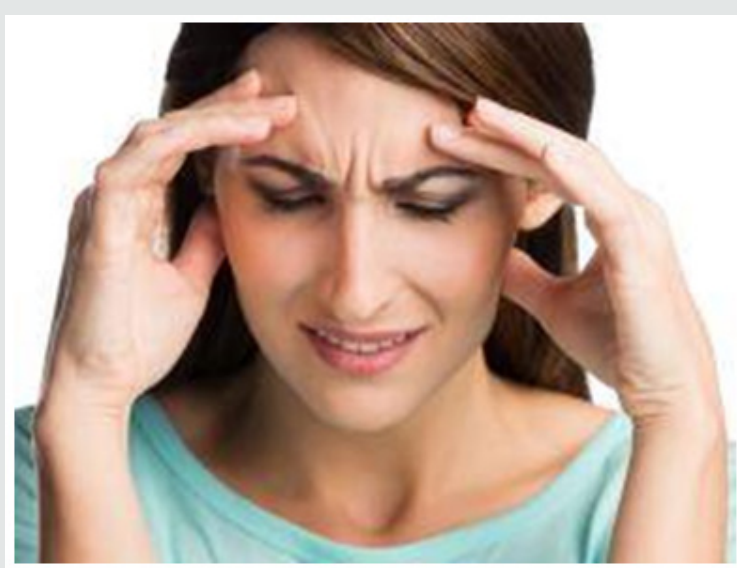

Figure.

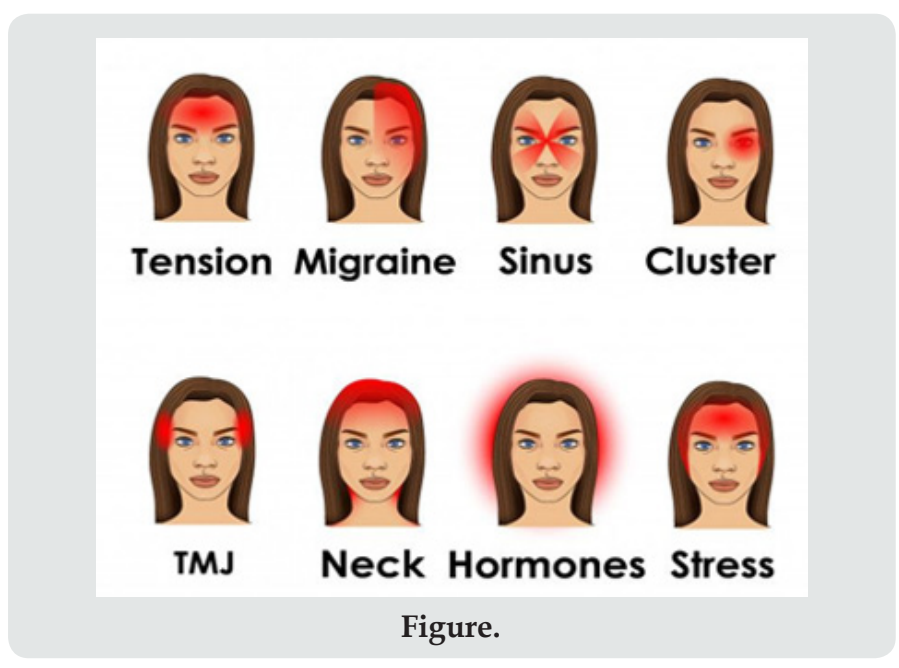

\section{Relation to the Eyes}

Ask These Questions to your Patient if they have Complaints Related to Headache (Table 1)

There are many diseases related to the eyes which can cause headache. But there are also some types of muscle imbalances which commonly occurs in young age. Let us discuss about the common causes of headache related to eye which occurs mainly in young adults.

Table 1:

\begin{tabular}{|c|c|}
\hline Signs & Questions to be asked to the patient \\
\hline Headache: & "Do you get a headache when you read or study?" \\
\hline Asthenopia: & $\begin{array}{c}\text { "Do you feel tiredness in the eyes when you read or } \\
\text { study?" }\end{array}$ \\
\hline Floating text: & $\begin{array}{c}\text { "Do you see the words appear to float on the page, } \\
\text { swim, jump or wiggle when you read or study?" }\end{array}$ \\
\hline $\begin{array}{c}\text { Facility } \\
\text { problems: }\end{array}$ & $\begin{array}{c}\text { "Do you have difficulties in quickly changing focus } \\
\text { from the board, to your textbook, and back to the } \\
\text { board again?" }\end{array}$ \\
\hline
\end{tabular}




\section{Uncorrected/Under corrected/Over corrected}

Refractive Error: The prevalence of Refractive error in young adults has increased in past few years [1], it is extremely important to perform the visual acuity test and retinoscopy before going to any other conclusion for the cause. As we all know, the visual acuity of the patient might be 20/20 even when there is manifest hyperopia or small amount of astigmatism is present. All young patient mandatorily undergo cycloplegic refraction regardless of their refractive status or visual acuity. Cycloplegic refraction gives the accurate amount of refractive status of the eye. Be it emmetropia or any types of ammetropia [1].

Convergence Insufficiency (CI): It is one of the most common cause of headache in young adults. It is an eye problem where eyes tend to drift outwards when reading or doing any close work. If this drifting happens it leads to double vision. To prevent the double vision, eyes must work extra hard to turn the eyes back in and this leads to all kinds of asthenopic symptoms like headache, eye pain etc.

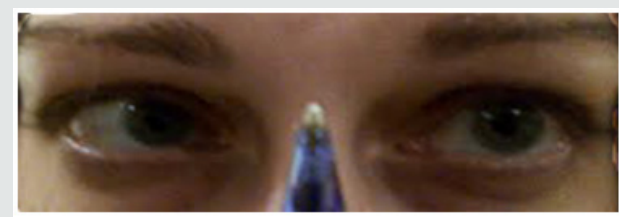

Figure.

- Treatment: One of the common treatments of $\mathrm{CI}$ is pencil push-up exercise and cat card exercise (Figure 1)

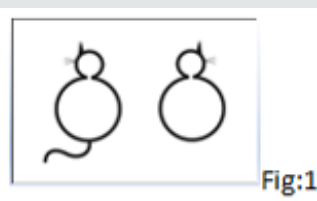

How to do the exercise

1. Hold the cat card at arm's length at the same level as your eye.

2. Then hold a pen half way between the card and your face.

3. Look at the top of the pen and

concentrate on it. It should appear as a single

image.

4. The cats behind the pen will then look like they are moving apart. The aim is for you to be able to see 3 cats behind the pen while still looking at the pen.

5. The 3 cats should look like this:

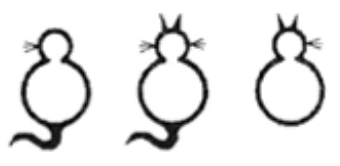

Figure 1.
Accommodative Spasm (AS): It is another common cause of headache in young adults. Due to continuous viewing/reading near objects, especially associated with stressful situations, the ciliary muscles remain in the condition of contraction. This causes headache and transient blurry vision for distance due to pseudomyopia [2]. Advising the patient to avoid near work for some time and do some stress relieving exercises can help.

Treatment: There are various exercises \& therapy treatments for the AS. Better consult an orthoptist/vision therapist's clinic for the treatments of these kind of problems.

Accommodative Insufficiency (AI): It is characterized by an inability to focus or sustain focus at near, demonstrated clinically by an insufficient amplitude of accommodation based on age. Children with poor general health are more prone to this condition.

Treatments: Hart Chart (Figure 2) will help and even cat card (Figure 1)

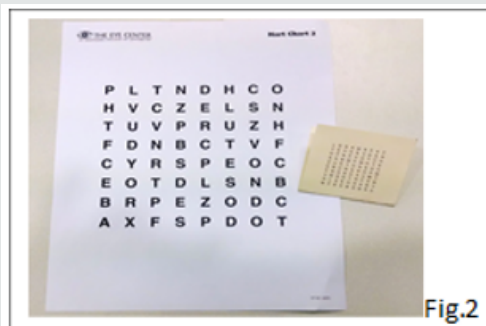

How to do exercise

There are two charts of rows of letters, one small and one large.

1.The patient typically stands 10 feet from the distance chart and holds the smaller chart in her hand

2.The patient alternates reading a line from the distance and near charts during the activity

3.There are three levels to be accomplished: near chart at arm's length, slowing moving toward the patient while reading, and as close as possible before becoming blurry.

Figure 2.

\section{References}

1. Onwuekwe I, Onyeka T, Aguwa E (2014) Headache prevalence and its characterization amongst hospital workers in Enugu, South East Nigeria. Head Face Med 10(48)

2. Hashemi H, Fotouhi A, Yekta A, Pakzad R, Ostadimoghaddam H, et al. (2017) Global and regional estimates of prevalence of refractive errors: Systematic review and meta-analysis. J Curr Ophthalmol 30(1): 3-22.

3. Image source : www.google.com 


\section{(C) (P) \\ This work is licensed under Creative \\ Commons Attribution 4.0 License}

To Submit Your Article Click Here:

Submit Article

DOI: $10.32474 /$ TOOAJ.2020.03.000151

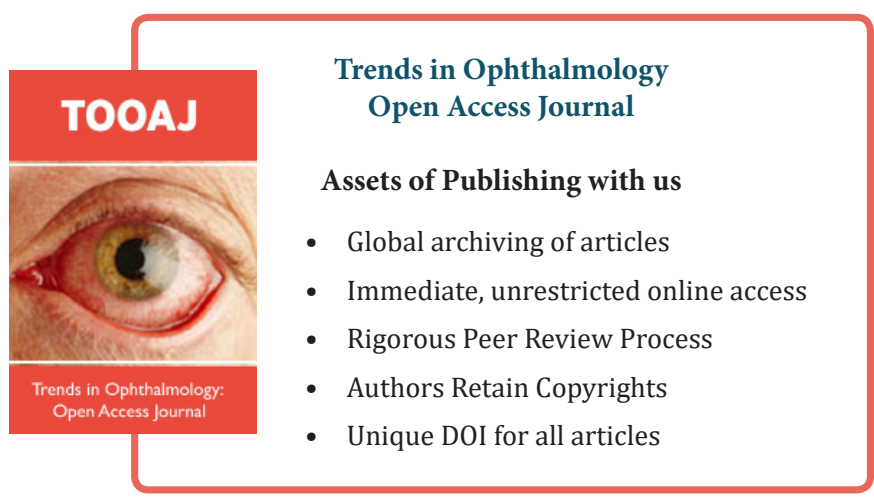

